\title{
Catalytic conversion of limonene over acid activated Serra de Dentro (SD) bentonite
}

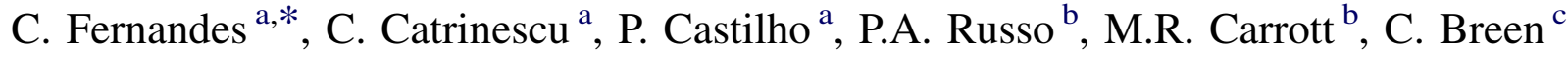 \\ ${ }^{a}$ Centro de Química da Madeira, Departamento de Química, Campus da Penteada, 9000-390 Funchal, Portugal

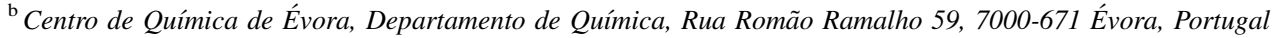 \\ ${ }^{\mathrm{c}}$ Materials and Engineering Research Institute, Sheffield Hallam University, Howard Street, Sheffield S1 1WB, UK
}

Received 22 June 2006; received in revised form 20 October 2006; accepted 27 October 2006

Available online 12 December 2006

\begin{abstract}
A series of acid-activated clay catalysts were prepared from a purified bentonite, rich in structural iron, collected at Serra de Dentro on the island of Porto Santo. The purified bentonite exhibited a surface area of $130 \mathrm{~m}^{2} \mathrm{~g}^{-1}$ which increased to values as high as $500 \mathrm{~m}^{2} \mathrm{~g}^{-1}$ following activation with $4 \mathrm{M} \mathrm{HCl}$ at $95{ }^{\circ} \mathrm{C}$ for $30 \mathrm{~min}$ (SD-4M-95-30). The ability of the activated samples to convert limonene to $p$-cymene was evaluated using a reaction time of $15 \mathrm{~min}$ at $80{ }^{\circ} \mathrm{C}$. The sample prepared using $3 \mathrm{M} \mathrm{HCl}$ at $95{ }^{\circ} \mathrm{C}$ for $30 \mathrm{~min}(\mathrm{SD}-3 \mathrm{M}-95-30)$ offered the optimum combination of surface area $\left(470 \mathrm{~m}^{2} \mathrm{~g}^{-1}\right)$ and acidity $\left(0.26 \mathrm{mmol} \mathrm{g}{ }^{-1}\right)$ and $95 \%$ of the limonene was converted to product. About $15 \%$ of the product mixture was $p$-cymene whilst non-volatile products and polymeric species made up 54\% of the product mixture. The presence of iron in the octahedral sheet of the SD bentonite appears responsible for the dehydrogenation activity. TG-MS analysis of acid activated samples, saturated with cyclohexylamine, reflected the dehydrogenation capabilities of the catalysts in that SD-3M-95-30 produced the most benzene and aniline as decomposition/ transformation products.
\end{abstract}

(C) 2006 Elsevier B.V. All rights reserved.

Keywords: Acid activated clays; Acidity; Catalysis; Limonene; $p$-Cymene

\section{Introduction}

p-Cymene (1-isopropyl-4-methylbenzene) finds many applications in the chemical industry including its use as a solvent in the ink and varnish industry, for the production of $p$-cresol and carvacrol, as an intermediate in the synthesis of anti-oxidants (e.g. BHT), in the production of synthetic resins, in perfumery and as a thermal fluid in heat exchanging systems [1-3]. The industrial production of $p$-cymene involves toluene alkylation [4]. However, although the starting material is low cost, the process requires harsh operating conditions and leads to a mixture of products that are difficult to separate. These challenges suggest that the search for an economically viable process, which provides high yields of pure $p$-cymene, has merit. Limonene, a cyclic monoterpene, is the major component (70-95\%) present in pine turpentine (Pinus pinea L.) $[5,6]$. However, despite being an abundant raw material that

\footnotetext{
* Corresponding author. Tel.: +351 291705 100; fax: +351 291705149 . E-mail address: cesaref@uma.pt (C. Fernandes).
}

is easy to obtain and purify, (-)-limonene is not highly valued despite having several applications in industry [7].

The isomerization of the double bonds in limonene is achieved using acid catalysts after which the ring can be aromatised over a ring dehydrogenation function such as $\mathrm{Cr}$ or $\operatorname{Pd}[8-10]$. The major challenge is the precise control of the acid site strength in order to minimise secondary reactions, such as polymerization and/or further isomerization of $p$-cymene. Krishnasamy and Yeddanapalli [8] have optimised the $\mathrm{K}^{+}$-ion content in $\mathrm{Cr}_{2} \mathrm{O}_{3} / \gamma-\mathrm{Al}_{2} \mathrm{O}_{3}$ catalysts to remove the strong acid sites, whereas Weyrich et al. [11,12] have reported that Cepromoted Pd/ZSM-5 catalysts offer enhanced selectivity towards $p$-cymene and slower catalyst deactivation rates. The acidity of the host zeolite also influenced the activity and selectivity towards $p$-cymene. De Stefanis et al. [13] have extended the range of acid solids to include large port zeolite USY, alumina-pillared clays (Al-PILC) and layered phosphates and found that the activity and selectivity towards $p$-cymene decreased as USY > Al-PILC. The use of acid activated clays in the transformation of terpenes and the conversion of $\alpha$ pinene to camphene and limonene is a well-documented test 
reaction [14-16] with which to evaluate the catalytic activity of the acid clays. Indeed, acid treated clays have been evaluated previously, in a non-systematic manner, for the production of $p$ cymene $[17,18]$.

Acid activation of montmorillonite, the main component of interest in bentonite ores, is frequently used for both scientific and industrial purposes and the products were used for the cracking of hydrocarbons (Houdry process) until their replacement by the more active and selective zeolites in the 1960s. The current drive to establish environmentally friendly technologies means that clay minerals, in general, and acid activated clays, in particular, are experiencing an increased interest with regard to their properties as catalysts for industrially important processes such as isomerization or Friedel-Crafts alkylation [19].

Acid treatment of clays results in two major outcomes: the substitution of the exchangeable cations by protons and the dissolution of metals ions from the clay structure, by depopulating the octahedral sheet. The acid activated materials produced are not stable in the $\mathrm{H}^{+}$-form, due to gradual exsolution of metal ions (mainly $\mathrm{Al}^{3+}, \mathrm{Mg}^{2+}$ and $\mathrm{Fe}^{3+}$ ), from the octahedral sheet which displace the $\mathrm{H}^{+}$ions on the cation exchange sites. This process is known as autotransformation [20]. Acid activation alters the number, strength and, perhaps, also the type of acid sites on the clay. It has been shown that clays with octahedral sheets rich in iron and magnesium are leached faster than the corresponding Al rich materials [21]. Removal of ions from the octahedral sheet leads to an increase in surface area in the early stages of the process. Subsequently, both the cation exchange capacity and the surface area decrease in parallel. The resulting open porous structure can offer a higher number of acid sites to reagents that are not sufficiently polar to enter the gallery and swell the untransformed part of the clay beyond the frontier of acid attack [14].

Porto Santo, a small island of ca. $70 \mathrm{~km}^{2}$ that belongs to the Madeira Archipelago, Portugal, offers some interesting bentonitic deposits from which clays have been extracted and used by the local population as both building materials (mainly roofing) and in popular sculpture [22]. Several authors have reported the extraction and characterisation of Porto Santo clays and, more recently, their pillared derivatives have been evaluated as catalysts for organic reactions and as adsorbents for pollutants $[19,23,24]$. Systematic studies, conducted by the current authors, on a series of samples collected from different deposits revealed important differences in mineralogical and chemical composition, and particularly surface area [25]. Consequently, the designation Porto Santo is considered too generic to properly distinguish between the different materials obtained from the selected deposits from this island.

The transformation mechanisms of limonene are well documented, and its aromatisation to obtain $p$-cymene presents an interesting route to an economically more valuable product provided that high yields and few by-products are obtained. In this study, the preparation and characterisation of an acid leached bentonite from Serra de Dentro is undertaken and the activity and selectivity of the acid activated derivatives towards the aromatisation of limonene to $p$-cymene is evaluated. The
Serra de Dentro clay is of particular interest because, in addition to displaying a higher than normal nitrogen surface area, it has a relatively high $\mathrm{Fe}_{2} \mathrm{O}_{3}$ content and the activation of smectites with high $\mathrm{Fe}_{2} \mathrm{O}_{3}$ contents, under mild conditions, have exhibited enhanced activity in the transformation of $\alpha$ pinene [26].

\section{Experimental}

\subsection{Catalyst}

Porto Santo contains several deposits of bentonite. Six locations were selected and samples collected, after discarding the top $10 \mathrm{~cm}$ of superficial materials to avoid weathering contamination. At least $3 \mathrm{~kg}$ of bentonite was collected from each location, coned, quartered, and sieved to the $<0.125 \mathrm{~mm}$ fraction. The resulting representative sample was decarbonated with hydrogen peroxide $\left(30 \mathrm{vol} . \%\right.$ at $\left.80{ }^{\circ} \mathrm{C}\right)$ to remove all organic matter, centrifuged at $6000 \mathrm{rpm}$, washed with deionised water and centrifuged again. The solids were suspended in deionised water, sonicated for $5 \mathrm{~min}$ in order to promote disaggregation and the $<2 \mu \mathrm{m}$ fraction was collected after $8 \mathrm{~h}$ sedimentation. All samples were characterised in terms of chemical composition (XRF), surface area $\left(\mathrm{N}_{2}\right.$ adsorption at $-196{ }^{\circ} \mathrm{C}$ ), basal spacing (XRD of pressed powders) and structure (FTIR spectra). The material obtained at Serra de Dentro (SD) was selected as the starting material for further work, since it contained the lowest amount of impurities within the group of samples collected [25].

The Na-exchanged form, subsequently referred to as Na-SD, was prepared using $1 \mathrm{M}$ aqueous sodium chloride solution. Excess $\mathrm{Cl}^{-}$was removed by dialysis. Chemical composition data of Na-SD indicated the presence of some residual calcium oxide $(0.5 \%)$, which could not be attributed entirely to an external calcium phase. Further Na-exchange was achieved by mixing $\mathrm{Na}_{3.5}$ EDTA with the clay, stirring the suspension overnight and centrifuging and washing the clay until the supernatant reached a stable, low conductivity.

Acid activated (AA) samples were prepared by mixing $10 \mathrm{~g}$ of $\mathrm{SD}$ with $300 \mathrm{~cm}^{3}$ aliquots of aqueous $\mathrm{HCl}$ (with selected concentrations) at 25 or $95{ }^{\circ} \mathrm{C}$, for different periods of time. The samples were then diluted with a large quantity of cold water to effectively terminate the leaching process, centrifuged and washed successively until a stable $\mathrm{pH}$ was achieved. The samples were air-dried for $24 \mathrm{~h}$. Samples are labelled as follows: acid concentration - temperature of activation contact time in minutes. For example, SD-6M-25-120 is the material obtained when a $10 \mathrm{~g}$ sample of $\mathrm{Na}-\mathrm{SD}$ was treated with $6 \mathrm{M} \mathrm{HCl}$ at $25^{\circ} \mathrm{C}$, for $120 \mathrm{~min}$.

\subsection{Characterization techniques}

XRD, XRF, thermal desorption of cyclohexylamine (CHA) followed by evolved gas analysis by mass spectrometry, IR spectroscopy and nitrogen adsorption at $-196{ }^{\circ} \mathrm{C}$ were used to evaluate the properties of the prepared catalysts. Beads for XRF analysis were prepared using the $\mathrm{Li}_{2} \mathrm{~B}_{4} \mathrm{O}_{7}$ fusion method and 
analysed on a Philips PW2400 XRF spectrometer. X-ray diffraction profiles of pressed powder samples were obtained using a Philips PW1830 X-ray diffractometer $(\mathrm{Cu} \mathrm{K} \alpha$; $\lambda=1.542 \AA$ ) operating at $40 \mathrm{kV}$ and $35 \mathrm{~mA}$. Diffractograms were recorded at $2^{\circ}(2 \theta) \mathrm{min}^{-1}$. Nitrogen adsorption isotherms were determined at $-196{ }^{\circ} \mathrm{C}$ on a CE Instruments Sorptomatic 1990, using helium (for dead space calibration) and nitrogen of 99.999\% purity supplied, respectively, by Linde and Air Liquide. Prior to the determination of the adsorption isotherms, the samples were outgassed for $8 \mathrm{~h}$ at $150{ }^{\circ} \mathrm{C}$, achieved using a heating rate of $1{ }^{\circ} \mathrm{C} \mathrm{min}^{-1}$. TG data were recorded on a Mettler TG50 thermobalance equipped with a TC10A processor. Samples ( $10 \mathrm{mg}$ ) were transferred directly out of CHA vapour into the thermobalance and the desorption traces were recorded at a heating rate of $20{ }^{\circ} \mathrm{C} \mathrm{min}{ }^{-1}$ under a nitrogen flow of $25 \mathrm{~cm}^{3} \mathrm{~min}^{-1}$. Samples were conditioned for $15 \mathrm{~min}$ under flowing nitrogen to remove physisorbed CHA. FTIR spectra (KBr pellets) were recorded on a ATI Mattson Infinity apparatus, between 4000 and $400 \mathrm{~cm}^{-1}$, with a $4 \mathrm{~cm}^{-1}$ spectral resolution. Evolved gas analysis (EGA) was performed on a Thermo Unicam Synergic chemical analysis system (TG-MS) equipped with a Cahn TG131 thermobalance; CHA saturated samples were heated from 25 to $800{ }^{\circ} \mathrm{C}$, at atmospheric pressure, under $\mathrm{N}_{2}$ flux and the evolved gases transferred to a MS Automass System 2, Unicam, via silica lined stainless steel transfer lines, maintained at $250^{\circ} \mathrm{C}$. During 'real time' TG-MS analysis the mass spectrometer scanned 4-500 amu every $1.5 \mathrm{~s}$.

\subsection{Catalytic test}

Limonene and $n$-decane were dried over anhydrous magnesium sulphate prior to use. The optimum time and temperature for the catalytic process were identified after studying a wide range of potential conditions. The product yields reported here were obtained after $15 \mathrm{~min}$ at $80^{\circ} \mathrm{C}$ in $10 \mathrm{~mL}$ glass vials. The stirrer speed was chosen to ensure that reaction rates were not under diffusion control.

Before reaction, $100 \mathrm{mg}$ of catalyst was thermally activated at $150{ }^{\circ} \mathrm{C}$ for $16 \mathrm{~h}$, under air, in the reaction vessel. To avoid the introduction of water, the activated clays were suspended in dry $n$-decane, and the glass vials were closed and transferred to an oil bath, preheated at $80{ }^{\circ} \mathrm{C}$. After being cooled to the reaction temperature over a period of $15 \mathrm{~min}, 0.5 \mathrm{~mL}$ limonene was injected into the vial and this marked the start of the reaction. At the end of the reaction the vials were cooled, opened, and the catalyst was separated using a syringe filter. The filter had no influence on the reaction products and no further reaction occurred during storage. The products were identified by GCMS (Varian Saturn 3) and quantified by capillary GC with FID detection with the $n$-decane acting as the internal standard.

\section{Results and discussion}

\section{1. $N a-S D$}

Na-SD was characterised using XRD, XRF, nitrogen adsorption and spectroscopic techniques.
Table 1

Chemical composition, surface area, basal spacing and CEC of Na-SD

\begin{tabular}{lc}
\hline Chemical composition/oxide (\%) & \\
$\mathrm{Na}$ & 2.6 \\
$\mathrm{Mg}$ & 3.4 \\
$\mathrm{Al}$ & 20.5 \\
$\mathrm{Si}$ & 57.4 \\
$\mathrm{~K}$ & 0.9 \\
$\mathrm{Ca}$ & 0.5 \\
$\mathrm{Ti}$ & 3.3 \\
$\mathrm{Fe}$ & 10.3 \\
Others & 1.1 \\
$A_{\mathrm{BET}}\left(\mathrm{m}^{2} \mathrm{~g}^{-1}\right)$ & 130 \\
$d_{\text {O01 }}(\AA)$ & 14.9 \\
$\mathrm{CEC}\left(\right.$ mequiv./100 $\left.^{\mathrm{g}}\right)$ & 81 \\
\hline
\end{tabular}

Nitrogen adsorption data revealed that SD exhibits higher surface areas $\left(130 \mathrm{~m}^{2} \mathrm{~g}^{-1}\right)$ than normally observed for smectites [27]. These features may be attributed in part to the small size of the constituent particles. The cation exchange capacity (CEC) was determined using the method suggested by Rhodes and Brown [28], and a value of 81 mequiv./100 $\mathrm{g}$ was obtained.

Elemental analysis using X-ray fluorescence (Table 1) shows that the sodium exchange procedure was successful. NaSD presents a high percentage of iron together with reasonable amounts of magnesium and titanium. Quantitative X-ray powder diffraction was performed on Na-SD (by Macauley Analytical Services; data not presented) and results, obtained using the reference intensity ratio (RIR) method, showed that the material had a high clay mineral content (ca. 92\%) with small amounts of quartz (4.6\%), plagioclase $(1.5 \%)$, anatase $(2.7 \%)$ and apatite $(2.0 \%)$. There was some evidence for trace amounts of kaolin, which was confirmed using FTIR spectra (vide infra). Glycolation indicated that the sample was monominerallic in terms of the swelling clays present, although the 060 peak (at $62.5^{\circ} 2 \theta$ ) was quite broad which could indicate the presence of a range of octahedral compositions.

Peaks at 3694 and $692 \mathrm{~cm}^{-1}$ in the FTIR spectrum of Na-SD confirmed the presence of kaolin while the peak at $3622 \mathrm{~cm}^{-1}$ was typical of an aluminium rich dioctahedral sheet. The $\mathrm{OH}$ bending bands at 917,876 and $836 \mathrm{~cm}^{-1}$ were readily assigned to $\mathrm{Al}_{2} \mathrm{OH}, \mathrm{AlFeOH}$ and $\mathrm{AlMgOH}$ groups, respectively, reflecting the partial octahedral substitution of $\mathrm{Al}$ by $\mathrm{Mg}$ and Fe. The shoulder near $620 \mathrm{~cm}^{-1}$ was attributed to the Al-O-R $(\mathrm{R}=\mathrm{Al}$ and $\mathrm{Mg})$ vibration of octahedral atoms. However, there was no clear evidence for the $820 \mathrm{~cm}^{-1}$ band associated with $\mathrm{Fe}_{2} \mathrm{OH}$, which is indicative of the absence of $\mathrm{Fe}$ domains in the octahedral sheet. The band at $795 \mathrm{~cm}^{-1}$ together with a shoulder near $1100 \mathrm{~cm}^{-1}$ may reflect the presence of cristobalite, but it was not detected during the quantitative XRD study. The strong band centred at $1039 \mathrm{~cm}^{-1}$ ( $\mathrm{Si}-\mathrm{O}$ stretching vibrations) together with those at and 526 and $471 \mathrm{~cm}^{-1}$ ( $\mathrm{Si}-\mathrm{O}-\mathrm{Al}$ and $\mathrm{Si}-\mathrm{O}-\mathrm{Si}$ bending vibrations, respectively) are typical of tetrahedral $\mathrm{Si}-\mathrm{O}$. Broad bands at 3427 and $1629 \mathrm{~cm}^{-1}$ were attributed to the $\mathrm{OH}$ stretching and bending vibrations of molecular water, respectively. A band at $1427 \mathrm{~cm}^{-1}$ could indicate the presence of a carbonate phase 

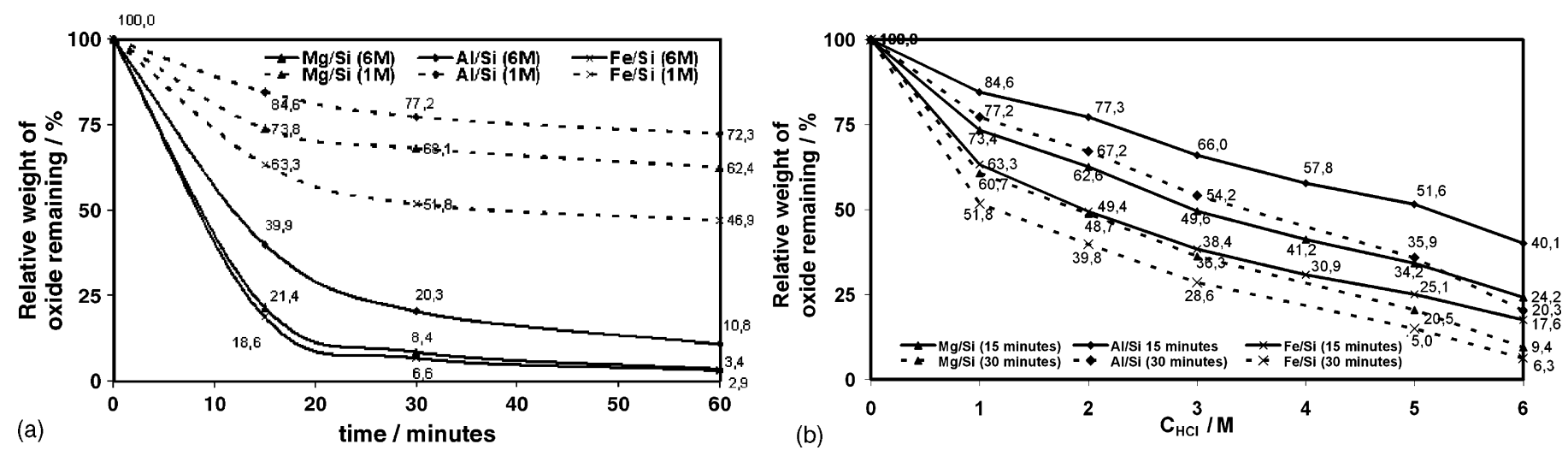

Fig. 1. (a) Relative weight percentage of $\mathrm{Al}, \mathrm{Mg}$ and Fe oxides remaining after acid treatments at $95{ }^{\circ} \mathrm{C}$ (full line: $6 \mathrm{M}$ series; dotted line: $1 \mathrm{M}$ series). (b) Relative weight percentage of $\mathrm{Al}, \mathrm{Mg}$ and $\mathrm{Fe}$ oxides remaining after $15 \mathrm{~min}$ (full line) and $30 \mathrm{~min}$ (dashed line) acid treatments at $95{ }^{\circ} \mathrm{C}$ with $\mathrm{HCl}$ solutions of different concentration.

or an ammonium cation. The rigorous Na-exchange procedures employed resulted in a very low $\mathrm{CaO}$ content (Table 1), but the presence of a calcium carbonate phase cannot be completely discarded [29]. The FTIR spectrum together with the quantitative XRD profiles are consistent with a material containing a high percentage of an aluminium rich dioctahedral smectite, with partial isomorphic substitution of $\mathrm{Al}$ by $\mathrm{Mg}$ and $\mathrm{Fe}$ and $\mathrm{Si}$ by $\mathrm{Al}$ in the octahedral and tetrahedral sheets, respectively, contaminated with anatase, kaolin, quartz and cristobalite. The peaks assigned to anatase in the XRD diffractogram are quite broad, which is consistent with the possible presence of some iron in its structure. Raman and Mössbauer spectra collected from Na-SD and raw SD did not support the presence of substantial quantities of pure iron oxides. The majority of the iron was present as two ferric doublets in the Mössbauer spectrum which remained at low temperatures. One, or perhaps two, magnetic phases were present, but were too weak to identify clearly even at $77 \mathrm{~K}$ [30].

\subsection{Acid activated samples}

XRF data obtained for the solid products, reported as metal/Si ratios, as a function of contact time and acid concentration are presented in Fig. 1. Si is known to be only marginally depleted by acid attack and was thus chosen as an internal reference. As expected, longer contact times and higher acid concentrations, caused more extensive metal depletion with $\mathrm{Fe}$ and $\mathrm{Mg}$ being removed at a faster initial rate than Al. Even the more harshly treated samples retained detectable quantities of the octahedral cations $(10.8,3.4$ and $2.9 \%$ of the initial $\mathrm{Al} / \mathrm{Si}, \mathrm{Mg} / \mathrm{Si}$ and $\mathrm{Fe} / \mathrm{Si}$ ratios, respectively), which suggested that some portion of the clay structure was retained. XRD data (Fig. 2) and IR spectroscopic data (Fig. 3) confirmed this supposition.

The XRD traces of the catalysts prepared by mixing Na-SD with $\mathrm{HCl}$ solutions of increasing concentration, at $95^{\circ} \mathrm{C}$, for 30 min periods (Fig. 2) displayed a regular decrease in intensity of the $d_{001}$ peak (ca. $6.5^{\circ} 2 \theta$ ). Moreover, the 110,020 peak (at $19.7^{\circ} 2 \theta$ ) and 060 peak (ca. $62.5^{\circ} 2 \theta$ ) also decreased in intensity, but even for SD-6M-95-30, some evidence for the presence of the $001,110,020$ and 060 peaks remained.
The most obvious effect of the acid attack on the FTIR spectra of the acid activated clays (Fig. 3) were the changes in position and shape of the main band at ca. $1038 \mathrm{~cm}^{-1}$ and the reduction in intensity of the $526 \mathrm{~cm}^{-1}$ band. With increasing severity of acid treatment the $1038 \mathrm{~cm}^{-1}$ band shifted to higher wavenumbers and a band at ca. $1100 \mathrm{~cm}^{-1}$, attributed to the $\mathrm{Si}-$ $\mathrm{O}$ vibrations of three-dimensional amorphous silica [31], increased in intensity. The other diagnostic band for amorphous silica appeared at $800 \mathrm{~cm}^{-1}$ and progressively grew in intensity, whereas the bands characteristic of the octahedral population (920, 878 and $839 \mathrm{~cm}^{-1}$ for $\mathrm{Al}_{2} \mathrm{OH}, \mathrm{FeAlOH}$ and $\mathrm{MgAlOH}$, respectively) progressively decreased in intensity, which is consistent with the progressive removal of these metals. Moreover, the intensity of the $526 \mathrm{~cm}^{-1}$ (AlOSi) band, which reports the linkage between the tetrahedral and octahedral layers also decreased. Finally, a band at ca. $937 \mathrm{~cm}^{-1}$,

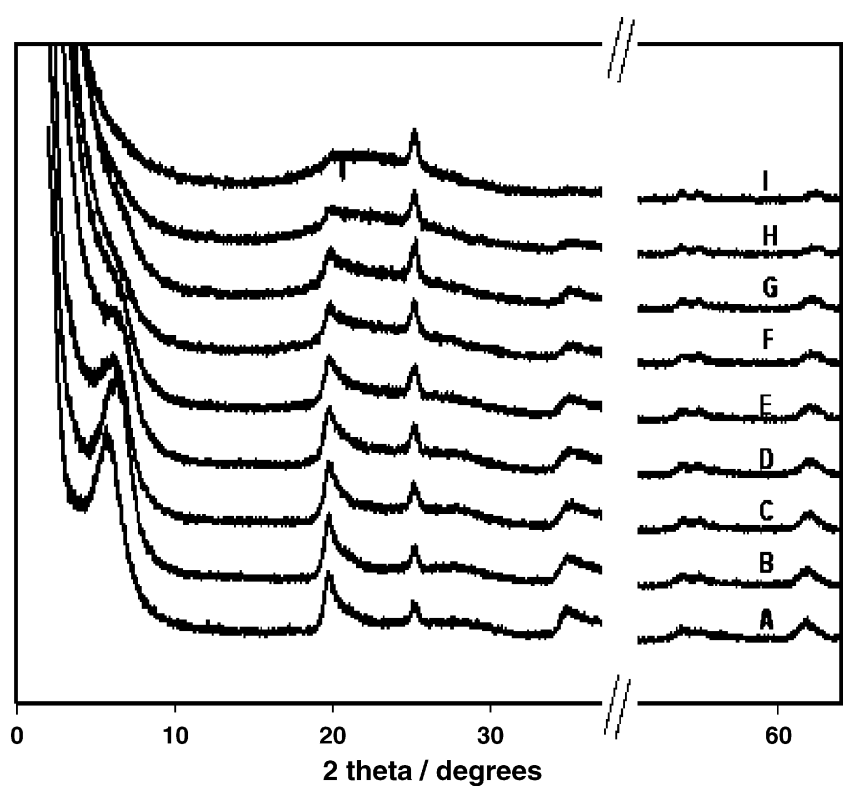

Fig. 2. XRD traces of AA SD-A: SD-1M-25-60, B: SD-6M-25-120, C: SD1M-95-30, D: SD-2M-95-30, E: SD-3M-95-30, F: SD-4M-95-30, G: SD-5M95-30, H: SD-6M-95-30 and I: SD-6M-95-60. 


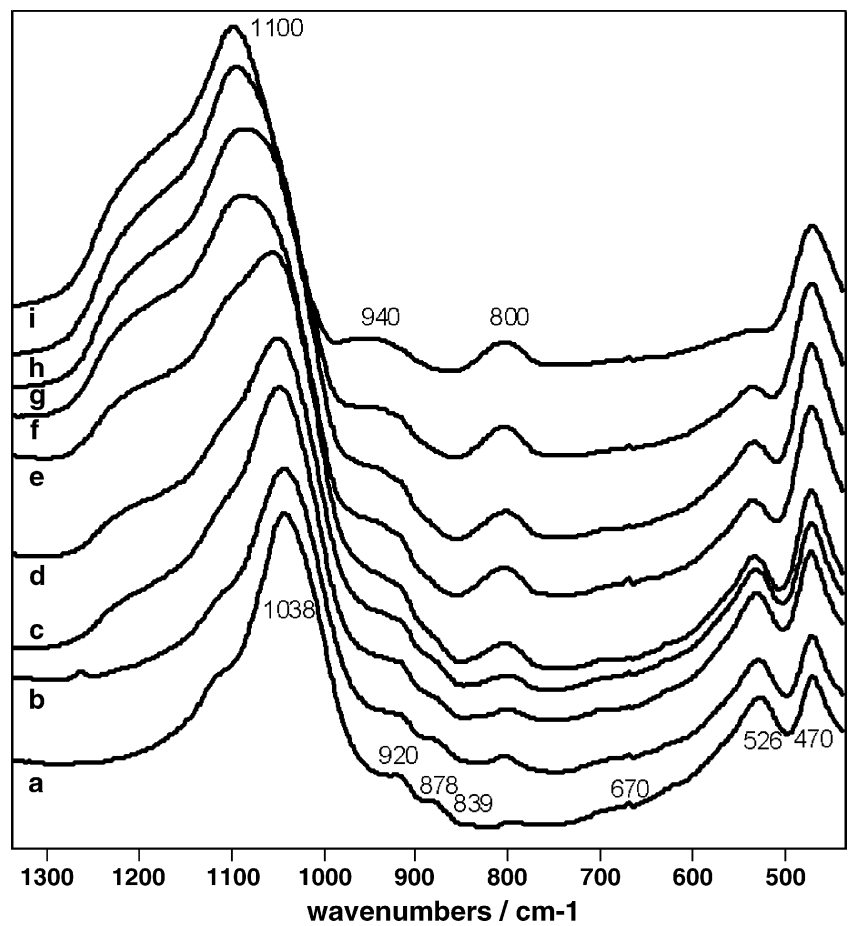

Fig. 3. FTIR spectra of (a) SD-1M-25-60, (b) SD-6M-25-120, (c) SD-1M-9530, (d) SD-2M-95-30, (e) SD-3M-95-30, (f) SD-4M-95-30, (g) SD-5M-95-30, (h) SD-6M-95-30 and (i) SD-6M-95-60.

attributed to the bending vibrations of $\mathrm{OH}$ groups linked to amorphous silica, increased in intensity.

Representative nitrogen adsorption-desorption isotherms of acid activated samples and that corresponding to the parent material (Na-SD) are presented in Fig. 4(a). The adsorption isotherm for $\mathrm{N}_{2}$ on Na-SD presents type I character at low relative pressures. This suggests the presence of primary micropores, while at high relative pressures the isotherm was close to type IIb and exhibited a hysteresis loop which is usually associated with adsorption of nitrogen on slit-shaped mesopores formed between plate-like particles [32]. The samples activated at room temperature and those activated using low acid concentrations at $95^{\circ} \mathrm{C}$ exhibited the same type of isotherm and hysteresis loop as the parent material. In contrast, the isotherms for the more harshly treated samples tended towards type IV and exhibited a different type of hysteresis loop which indicated that alterations in the mesoporosity had occurred.

The values of specific surface area of the samples under investigation, obtained by applying the Brunauer-EmmettTeller (BET) method to the $\mathrm{N}_{2}$ adsorption isotherms at $-196{ }^{\circ} \mathrm{C}$, are plotted as a function of the acid concentration used in Fig. 4(b). As anticipated, the samples prepared at room temperature only displayed a slight increase in surface area when compared to that for untreated Na-SD, even after activation with $6 \mathrm{M}$ acid for $60 \mathrm{~min}$. Acid activation at $95{ }^{\circ} \mathrm{C}$ resulted in a significant increase in surface area, with the effects depending on both the acid concentration and the contact time. The surface area increased with treatment time in $1 \mathrm{M}$ acid at $95{ }^{\circ} \mathrm{C}$, whereas treatment with $4 \mathrm{M}$ acid for 30 min maximised the measured surface area. Increasing the acid concentration to 5 and $6 \mathrm{M}$ at $95{ }^{\circ} \mathrm{C}$ caused a downturn in surface area. Indeed, increasing the treatment time, using $6 \mathrm{M}$ acid at $95^{\circ} \mathrm{C}$, to $60 \mathrm{~min}$ resulted in a surface area some $50 \mathrm{~m}^{2} \mathrm{~g}^{-1}$ less than the maximum. It was noted that the surface area values displayed different trends if the samples were grouped according to the time of contact at different acid concentration. For the samples prepared using the shorter contact time $(15 \mathrm{~min})$, the surface areas of the resulting materials increased in the same order as the acid concentration used in the treatment. However, for longer contact time (30 min), this trend was only observed up to a concentration of $4 \mathrm{M}$, and with higher acid concentration lower surface area materials were produced. The downturn in surface area was not pursued further because it has been noted previously by others $[33,34]$ and is generally attributed to the
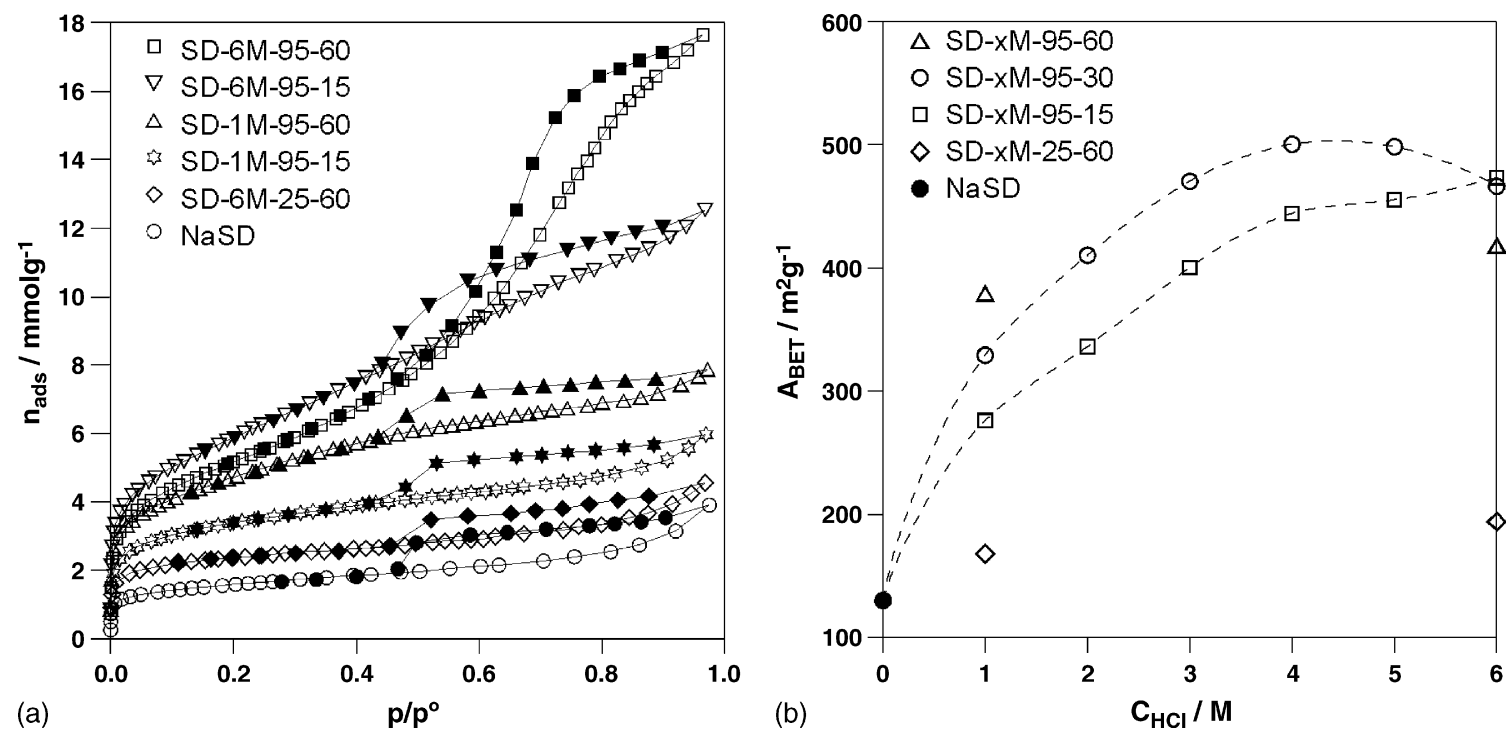

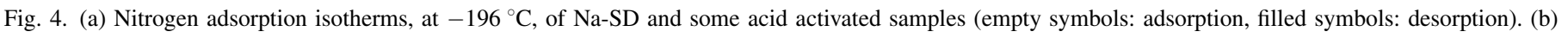
Specific surface area (BET method) of $\mathrm{Na}-\mathrm{SD}$ and acid activated SD samples. 
Table 2

Quantities of CHA desorbed in the 280 and $440{ }^{\circ} \mathrm{C}$ temperature interval

\begin{tabular}{ll}
\hline Sample & CHA desorbed $\left(\mathrm{mmol} \mathrm{g}^{-1}\right)$ \\
\hline SD-1 M-95-15 & 0.62 \\
SD-1 M-95-30 & 0.52 \\
SD-2 M-95-15 & 0.50 \\
SD-2 M-95-30 & 0.42 \\
SD-3 M-95-15 & 0.42 \\
SD-3 M-95-30 & 0.26 \\
SD-4 M-95-15 & 0.21 \\
SD-4 M-95-30 & 0.11 \\
SD-6 M-95-15 & 0.15 \\
SD-6 M-95-30 & 0.10 \\
\hline
\end{tabular}

onset of a 3D silica structure caused by bond formation between the silica fronds which are generated as the octahedral sheet is excessively depleted.

The thermal desorption of cyclohexylamine has been frequently used to evaluate the number of acid sites on clay catalysts [35]. The technique involves the determination of the weight loss between 280 and $440{ }^{\circ} \mathrm{C}$ and its conversion to the number of mmol of CHA desorbed. The relative ease of obtaining this quantity made it very popular even though the value obtained does not distinguish between cyclohexylamine bound to Brønsted or Lewis acid sites. Moreover, the method often reports high acidity values which are not reflected in the yields from tests of catalytic activity. For example, the presence of $\mathrm{Ca}^{2+}$-ions, which retain CHA to temperatures at which thermal $\mathrm{C}-\mathrm{N}$ bond cleavage occurs, can lead to a weight loss in the 280 and $440{ }^{\circ} \mathrm{C}$ region providing a 'measured acidity' [36]. Nonetheless, the method does provide reasonable estimates of the number of protons if acid-leached clays are exposed to cyclohexylamine vapour within 1 day of acid treatment. The quantities of CHA desorbed in the appropriate temperature interval (Table 2) shows, as anticipated from earlier work [21] that the estimated acidity values decreased as the severity of the acid treatment increased.

\subsection{Catalytic tests-limonene conversion}

In the presence of acid or, in this case, acidic sites available at the clay surface, limonene reacted to form a mixture of products (Scheme 1). The reaction mixture consisted of a volatile fraction, containing GC-quantifiable components, and a non-volatile fraction (high-molecular weight compounds). The main volatile reaction products, identified by GC-MS, were: $p$-menthenes (two main isomers), $\alpha$-terpinene, $\gamma$-terpinene, $p$-cymene, terpinolene and isoterpinolene, confirming the reaction sequence presented in Scheme 1. A few additional small peaks were present in the chromatogram but their low concentration precluded their identification by GC-MS, so they were neglected. They accounted for 4-6 wt.\% of the total reaction mixture. At the end of the process, when all terpenes are consumed, the non-volatile fraction dominated the product distribution, reaching yields of up to $55 \mathrm{wt} . \%$.

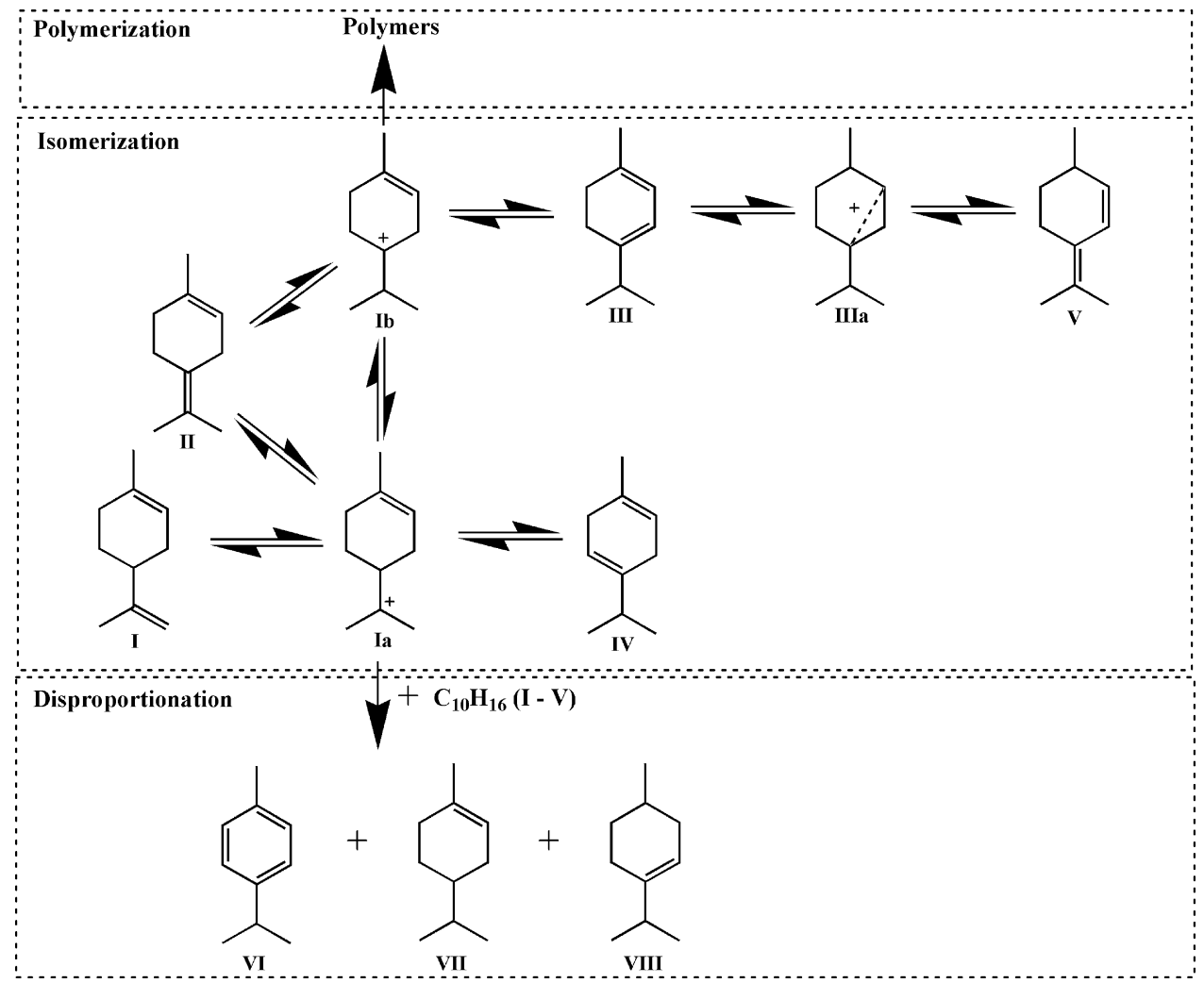

Scheme 1. Limonene isomerization/aromatization mechanisms-I: limonene, II: terpinolene, III: $\alpha$-terpinene, IV: $\gamma$-terpinene, V: iso-terpinolene, VI: $p$-cymene, VII: 1-p-menthene and VIII: 3-p-menthene. 


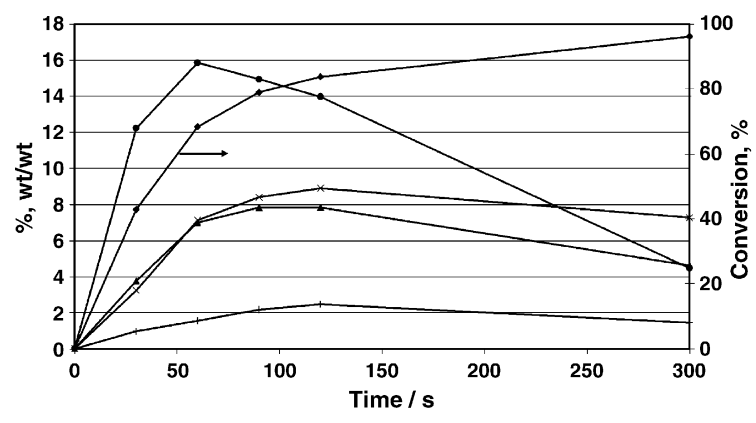

(a)

$\star$ a-terpinene $*$ g-terpinene $\rightarrow$-terpinolene $\rightarrow$ isoterpinolene $\rightarrow$-limonene

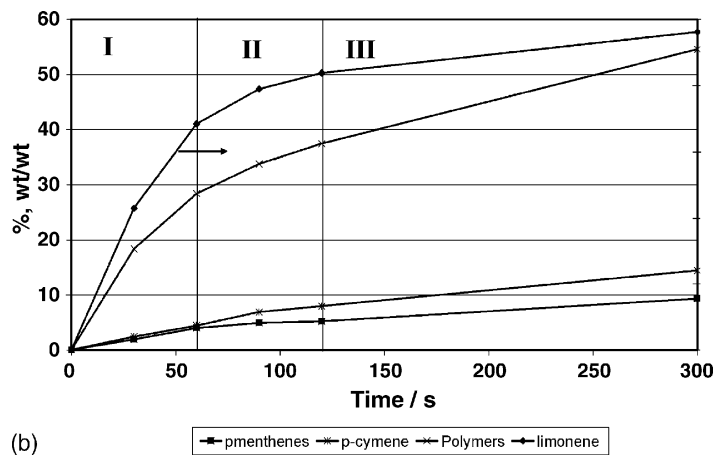

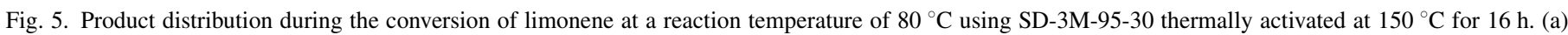
Isomerization products and (b) other products (disproportionation, polymerization).

Fig. 5 uses the catalytic test results obtained over SD-3M95-30, following pretreatment at $150{ }^{\circ} \mathrm{C}$, to illustrate how the total conversion and the product distribution varied with time. The overall shape of the curves was the same, although differing in time and yield, depending on the severity of leaching to which Na-SD was subjected. Preliminary scoping studies revealed that the evolution of the reaction products with time conformed with the results for typical acid catalysts including those reported for several liquid and solid acids, including silica and acid forms of ion-exchange resins [37].

Under these reaction conditions, three competitive reactions take place: (1) isomerization, (2) disproportionation to equimolar quantities of $p$-cymenes and $p$-menthenes and (3) polymerization. Examination of the hydrogen shift reactions revealed that the process could be formally divided into three stages. In the early part of the reaction (stage I) there was a steep decrease in limonene concentration (zero-order kinetics) accompanied by the production of the main reaction intermediates. The initial reaction rates decreased in the order: terpinolene $>\alpha$-terpinene $>\gamma$-terpinene $>$ isoterpinolene.

The linear decrease in limonene concentration terminated as the concentration of terpinolene reached a maximum (end of stage I, $60 \mathrm{~s}$ ), after which the consumption of terpinolene followed zero-order kinetics whereas the concentrations of $\alpha$-terpinene and $\gamma$-terpinene remained essentially constant (stage II, $120 \mathrm{~s}$ ). During stage III, which occured at $\geq 90 \%$ limonene conversion, the content of all dienes in the mixture decreased continuously, until their complete disappearance at prolonged reaction time ( $\geq 15 \mathrm{~min})$.

Fig. 5(b) reports the distribution of the products arising from a more extensive (than isomerization) transformation of the $p$ menthadienes. Clearly, both the disproportionation and polymerization processes began during stage I but, unlike the isomerization products, which reached a maximum and then began to decrease, the yields of $p$-cymene, menthenes and nonvolatile species continued to increase throughout stages II and III. The formation of similar amounts of $p$-cymene and $p$ menthenes suggested that the primary route to $p$-cymene occurred through the disproportionation of hydrogen in the dienes. In the late stages of the reaction the $p$-menthenes content remained almost constant, while the concentration of $p$ cymene increased slightly. This increase in the $p$-cymene/ $p$ - menthenes molar ratio could indicate that hydrogen redistribution was taking place between a $p$-methadiene and a polymeric species or that the aromatic molecule was produced through an additional oxidation mechanism (on acid Lewis sites). The polymerization process dominated stage III, as the content of the dienes with conjugated double bonds $(\alpha-$ terpinene and isoterpinolene) reached a maximum. Their condensation, via a Diels-Alder process, led to the formation of high molecular weight products, reaching up to $55 \mathrm{wt} . \%$ at the end of the process.

Fig. 6 illustrates the distribution of products obtained over the range of acid-treated SD. The crosses present the limonene conversion values which provide a visual indication of the progress of the reaction (in conjunction with Fig. 5). Na-SD was completely inactive under these conditions and required longer times at higher temperatures to effect any conversion of limonene. The much higher limonene conversion values over the acid-leached clays confirmed that the reaction had progressed much further during the 15 min reaction time and was in stage II (with the possible exception of the clays treated with $1 \mathrm{M} \mathrm{HCl}$ ). Hence, the reaction rate over the individual catalysts increased from left to right in Fig. 6. It is evident from the product yields and distributions that the catalytic activity, expressed as limonene conversion, increased with the severity of the acid activation treatment and maximised over samples SD-3M-95-30 and SD-4M-95-15 in direct correlation with the measured surface areas. This behaviour appeared to be incompatible with the acidities estimated from the desorption of cyclohexylamine (Table 2), but there is a complex interplay between the acidity and surface area that will be further explored below. The production of polymers reached a maximum over SD-3M-95-30 and SD-4M-95-15. These two catalysts also provided the highest yield of, and greatest selectivity towards the target species, $p$-cymene. Note that the yield of $p$-cymene decreased over SD-4M-95-30, and over the samples prepared using $6 \mathrm{M}$ acid, and the yield of terpinolene increased.

The catalysts prepared under mild conditions displayed a higher total number of acid sites, but a lower limonene conversion than the severely-leached clays. Hence, it seems that, for mildly treated clays, only a fraction of the acid sites was accessible for reaction, and the available surface area 


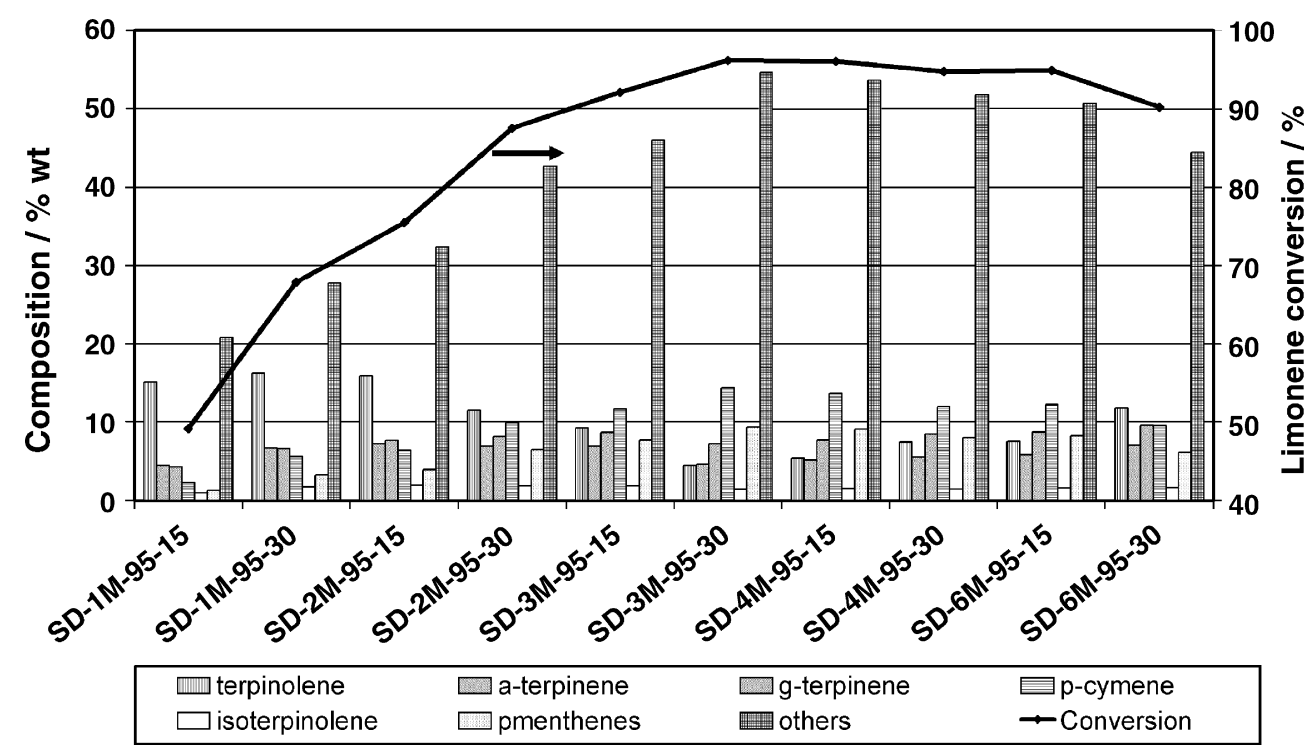

Fig. 6. Distribution of products over SD leached using the given acid contents for $15 \mathrm{~min}$ at $80{ }^{\circ} \mathrm{C}$. The acid treated clays were pretreated at $150{ }^{\circ} \mathrm{C}$ for $16 \mathrm{~h}$ prior to their use in the reaction.

coupled with the accessibility of the active (acid) sites play an important role in controlling the catalytic process. These results agree with the previous findings of Breen et al. [21] and Vaccari [38] who explained that the acid-treatment conditions required to maximize the catalytic activity depends on the precise reaction of interest. Reactions involving polar molecules can be efficiently catalysed by mildly treated clays because the large number of acid sites available on the internal surface are accessible to the polar reactant. In contrast, non-polar molecules are only able to react at the accessible external face and edge sites on the surfaces of the clay platelets. Consequently, the reactions involving non-polar reagents require more harshly treated clays, and the activity depends on the complex interrelation between available surface area and accessible acidity. Similar observations have been reported by Rhodes and Brown for the isomerization of $\alpha$-pinene to camphene and limonene [34].

Thus, the number of available acid sites on the external surfaces is most likely to be responsible for the observed order in the catalytic activity. It is reasonable to assume that the most active catalysts for the production of $p$-cymene (within the current constraints of reaction time and temperature), i.e. SD3M-95-30 and SD-4M-95-15, offer the most appropriate combination of available surface and accessible acidity for the transformation of limonene. The number of acid sites estimated from cyclohexylamine desorption are 0.26 and $0.21 \mathrm{mmol}$ (g clay) $^{-1}$. This may not reflect the number of acid sites available to the limonene molecules because cyclohexylamine is a very polar reagent which will be able to access those galleries still remaining beyond the progress of the acid leaching process. Thus, it is a considerable challenge to determine the number of acid sites available to non-polar reagents because the most commonly used probes of acidity are very polar and can access acid sites not available to the nonpolar reagents.
In an attempt to evaluate the number of acid sites contributing to the catalytic activity a representative catalyst was poisoned using increasing amounts of pyridine. In an additional experiment, using the same catalyst, the protons (generated during acid activation) were replaced by back exchanging the catalysts with Na-ions. This approach was adopted to ascertain whether the acid treatment generated any sites, acidic or otherwise, which were not removed or poisoned by the Na-back exchange procedure. One particular target was to ascertain whether there were any active Lewis sites produced during the acid leaching and subsequent thermal pretreatment. The product yields and distributions obtained using these two different approaches are presented in Fig. 7. Clearly, increasing the amount of pyridine to amounts in excess of $0.2 \mathrm{mmol} /$

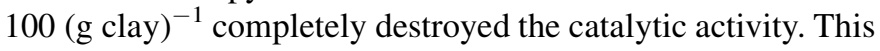
value is in good agreement with the acidity value $\left(0.26 \mathrm{mmol} \mathrm{g}^{-1}\right)$ estimated from CHA desorption (Table 2), but may indicate that only ca. $80 \%$ of the sites estimated using

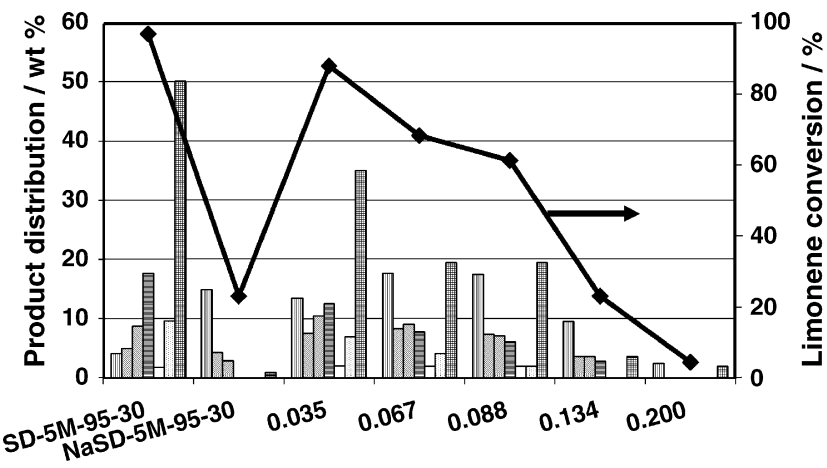

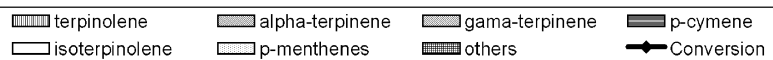

Fig. 7. The influence of back exchange with $\mathrm{Na}$-ions and poisoning with increased amounts of pyridine on the product distribution over SD-5M-9530 (the numbers on the $X$-axis refer to $\mathrm{mmol}$ of pyridine per gram of clay). 
CHA were accessible and/or active in the transformation process. Like cyclohexylamine, pyridine is not selective and will poison both Brønsted and Lewis acid sites. Therefore, the Na-back exchanged samples may provide further evidence for the presence or otherwise of Lewis acid sites. If the Lewis sites are part of the structure, rather than an adsorbed cation such as $\mathrm{Al}, \mathrm{Mg}$ or $\mathrm{Fe}$ generated during the leaching process, then the Na-ions should not have a significant influence on their activity. The quantities of limonene converted, together with the amount of polymers formed indicated that the Na-back exchanged samples were relatively unreactive and resided in stage I of the conversion process where comparatively large amounts of terpinolene, $\alpha$ - and $\gamma$-terpinene would be anticipated. Nonetheless, the product profiles were equivalent to those obtained using Na-SD treated with $1 \mathrm{M}$ acid (SD-1M-95-15) indicating the presence of a small number of accessible acid sites-which on balance must be considered to be Lewis acidic in nature. The moderately enhanced surface area of the Na-back exchanged sample may be increasing the accessible surface near to the Lewis acid sites present in Na-SD.

SAz-1 is a well known montmorillonite of relatively high CEC (120 mequiv./100 g clay) and low structural iron content $\left(\mathrm{Fe}_{2} \mathrm{O}_{3}=1.6\right.$ wt. \%). The Al- and Ni-exchanged forms of SAz-1 have recently been compared to the same cation-exchanged forms of $\mathrm{SD}$ in the transformation of limonene to $p$-cymene [39]. Al- and Ni-SD were significantly more active than Al- and $\mathrm{Ni}-\mathrm{SAz}-1$, in that the conversion of limonene over SD was $>80 \%$ but $<5 \%$ over SAz. A similar comparison has been undertaken here using samples of SAz-1 leached using 1, 3 and $6 \mathrm{M} \mathrm{HCl}$ at $95{ }^{\circ} \mathrm{C}$ for $30 \mathrm{~min}$. These leaching times were selected [21] to produce catalysts of similar octahedral depletion to the SD samples prepared here. Once again, the catalysts based on SAz-1 were less active than those based on SD. The acid leached SAz-1 catalysts produced similar quantities of the non-volatile products but produced very little $p$-cymene. These results show that surface area and acidity alone are not sufficient to produce usable quantities of $p$ cymene and point to the need for dehydrogenation sites which are probably associated with the iron in the SD structure.
The transformation of limonene (and other terpenes) is usually attributed to Brønsted sites, which protonate the unsaturated molecule, thus initiating a network of reactions, including dehydrogenation and polymerization. However, the $p$-cymene production over SAz-1 was very low perhaps suggesting, together with the moderately enhanced yield over the Na-back exchanged sample, Na-SD-5M-95-30 that structural Lewis acid sites maybe involved in the catalytic conversion of limonene. Indeed, there is evidence [40] that the conversion of some terpenes ( $\alpha$-pinene, trans-isolimonene and $\alpha$-terpinene) over zeolites is probably not catalyzed by Brønsted acid sites. These authors used deuterated mordenite as the catalyst, but were unable to find any deuterium incorporated in the starting terpene leading them to suggest that the rearrangements occurred over Lewis acid sites. Moreover, electron paramagnetic resonance (EPR) studies, have shown that the incorporation of the three terpenes (listed above) in mordenite gave rise to the same radical cation, i.e. that of $\alpha$-terpinene. Thus, a Lewis acid site could behave as an "electron-hole" and accept one electron from the electron-rich terpene, giving rise to the corresponding radical cation, which undergoes further conversion to the more stable $\alpha$-terpinene radical cation. Furthermore, De Stefanis et al. [13] have also shown that $\alpha$-pinene and limonene are readily converted over zeolites and PILCs, under Lewis acid conditions, with USY exhibiting a high selectivity $(>40 \%)$ towards $p$-cymene, the oxidation product of limonene. Finally, it has been shown [41] that the non-exchangeable acid sites (defect sites on the clay surface and coordinatively unsaturated edge sites in the lattice) are predominantly Lewis acidic and exhibit some catalytic activity in Friedel-Crafts alkylations.

The results presented here, for the catalysts derived from SD, could suggest that the reaction also proceeds over Lewis acid sites which are able to steer the reaction via two possible mechanisms. The first involves the adsorption of the exocyclic double-bound with formation of a primary carbonium ion, followed by a proton shift leading to a tertiary carbonium ion, from which terpinolene could be formed. The second possible explanation is that the Lewis site behaves as an "electron-

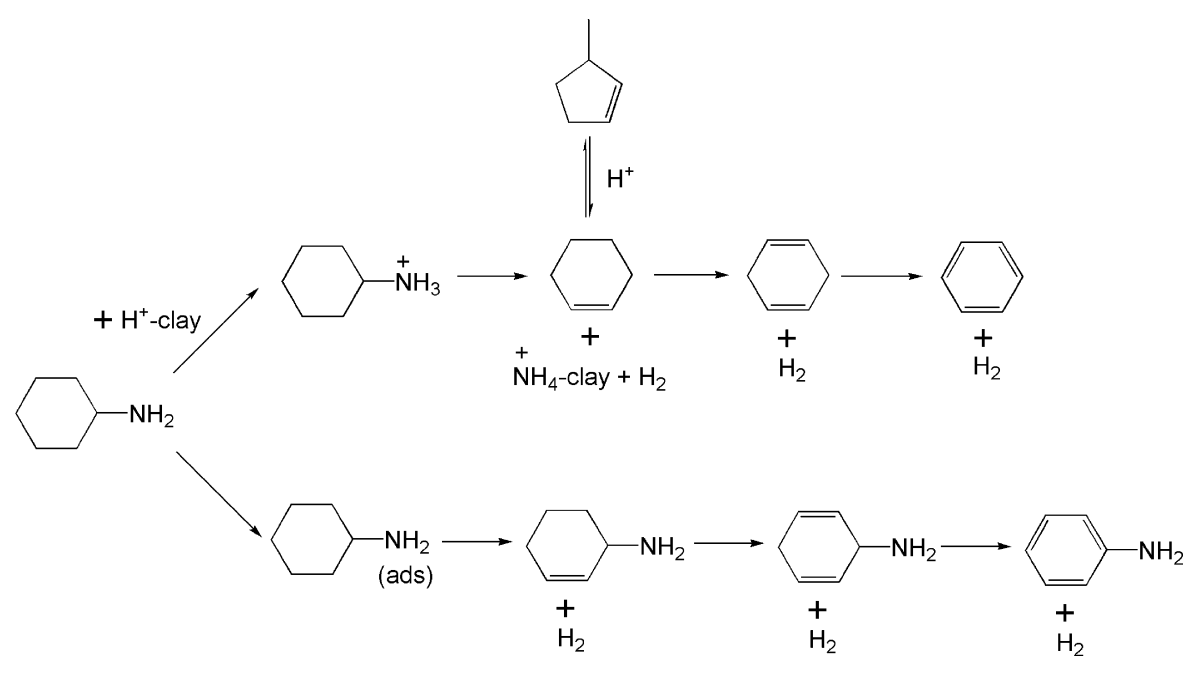

Scheme 2. Decomposition mechanism for acid controlled CHA degradation. 


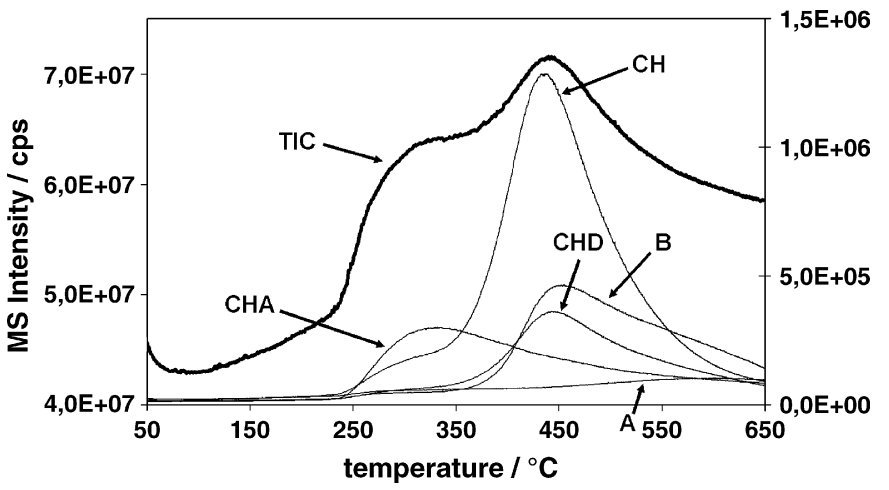

Fig. 8. Real time MS ion chromatograms for the desorption of CHA $(\mathrm{m} / z=99)$, $\mathrm{CH}(\mathrm{m} / \mathrm{z}=54), \mathrm{CHD}(\mathrm{m} / \mathrm{z}=77), \mathrm{B}(\mathrm{m} / \mathrm{z}=78)$ and aniline $(\mathrm{m} / \mathrm{z}=93)$ from SD$1 \mathrm{M}-15-95$ after a 7 days incubation period with CHA.

hole" and accepts one electron from the electron-rich $\alpha$ terpinene, giving rise to the radical cation of $\alpha$-terpinene. Afterwards, the radical cation dehydrogenates to $p$-cymene via an allylic radical. The formation of radical cations is known to promote the polymerization of dienes, and could explain the high content of polymers formed in the process [42].

\section{4. $T G-M S$ data}

Simple thermogravimetric CHA desorption profiles can provide an estimate of the number of acid sites (Table 2), but are unable to elucidate any differences that may exist between the different decomposition pathways over different materials. Real time TG-MS analysis of the decomposition products contributes to a more complete picture of the decomposition of CHA. Generally, CHA decomposition can be represented by Scheme 2
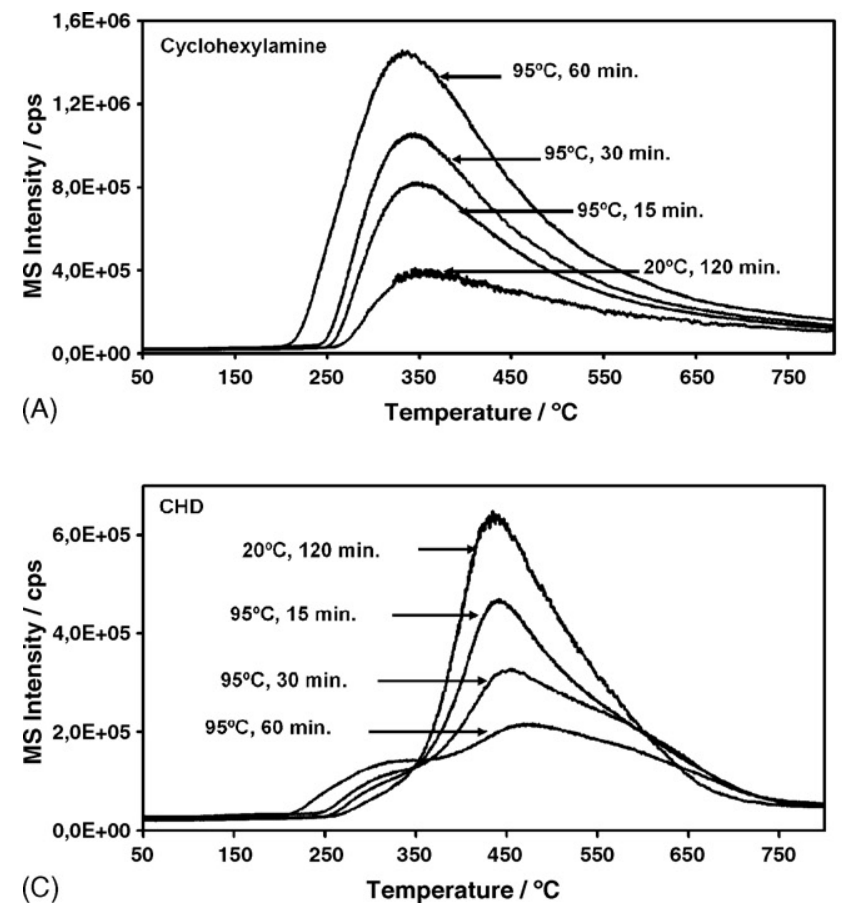

[43]. Binding to a Brønsted acid site produces protonated CHA, which can generate unbound cyclohexene $(\mathrm{CH})$ via Hofmann deamination leaving $\mathrm{NH}_{4}{ }^{+}$on the clay surface. Successive acid promoted dehydrogenation and isomerization reactions produces cyclohexadiene (CHD), which goes on to form benzene (B). The formation of methylcyclopentene (MCP) via ring isomerization over the acid sites is also a possibility.

Fig. 8 illustrates the information obtained from a typical real time mass spectrum for the desorption of CHA from SD-1M95-15. The total ion count is assigned to the left-hand axis while the intensities of the single ion species are given on the righthand axis. Generally, two peaks were present in the desorption profile. The lower temperature peak arises mainly from the desorption of CHA and water whereas the peak at higher temperature has been routinely associated with the acidity and hence catalytic activity of the clay catalyst under scrutiny $[21,44,45]$. This higher temperature peak arises from the desorption of decomposition/transformation products in addition to some unmodified CHA. $\mathrm{CH}, \mathrm{CHD}$ and benzene were evolved at successively higher temperatures.

Fig. 9 presents the single ion profiles for the evolution of $\mathrm{CHA}, \mathrm{CH}, \mathrm{CHD}$ and B from the samples treated with $6 \mathrm{M} \mathrm{HCl}$ (as a function of acid activation temperature and treatment time). The amount of unmodified CHA desorbed under the lower temperature peak increased as the severity of acid treatment increased, which was attributed to the increased surface area available (Fig. 4) to accommodate more CHA. Moreover, the temperature at which the peak maximum occurred, $T_{\max }$, decreased suggesting that, at least some of, the CHA was more loosely held. In contrast the quantity of all the decomposition products $(\mathrm{CH}, \mathrm{CHD}$ and $\mathrm{B})$ evolved under the higher temperature peak diminished, which was consistent with
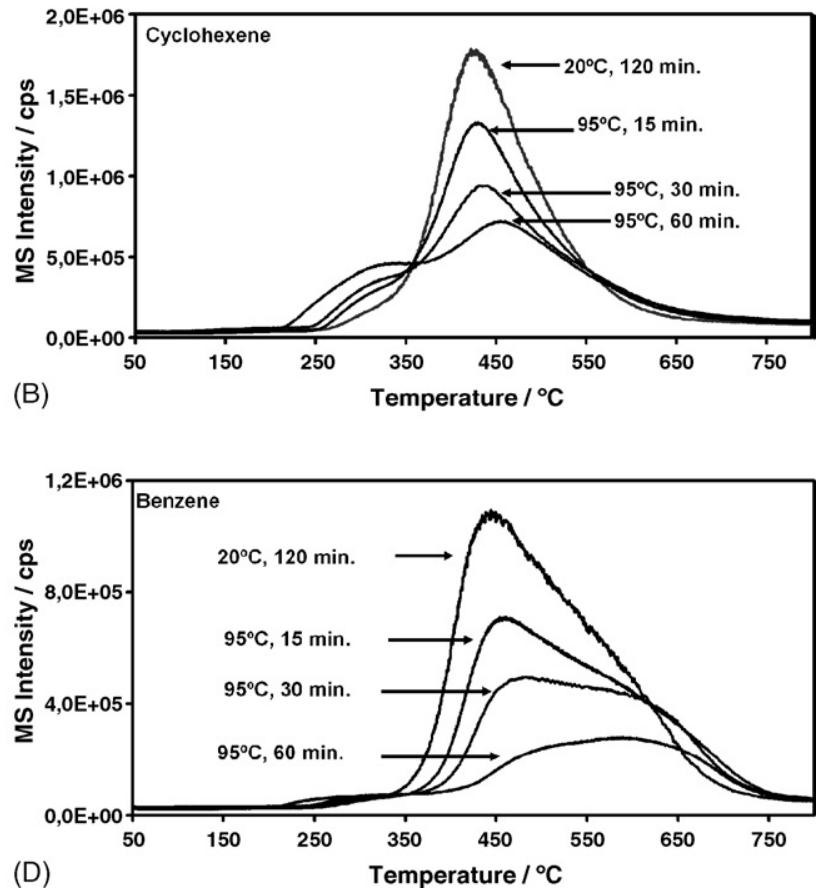

Fig. 9. Comparative MS single ion chromatograms for SD treated with $6 \mathrm{M} \mathrm{HCl}$ solutions at $25^{\circ} \mathrm{C}$ during 120 min and at $95{ }^{\circ} \mathrm{C}$ during 15 , 30 and 60 min. (A) $\mathrm{CHA}$ $(\mathrm{m} / z, 99),(\mathrm{B}) \mathrm{CH}(\mathrm{m} / z, 54),(\mathrm{C}) \mathrm{CHD}(\mathrm{m} / \mathrm{z}, 77)$ and (D) B $(\mathrm{m} / z, 78)$. 
the decrease in the total amount of CHA desorbed in the 280$440{ }^{\circ} \mathrm{C}$ region (Table 2 ) as the depopulation of the octahedral sheet progressed. The characterization data discussed above (XRD, XRF, FTIR spectra and surface area) confirmed that all the samples treated with $6 \mathrm{M} \mathrm{HCl}$ at $95{ }^{\circ} \mathrm{C}$ exhibited high degrees of structural decomposition. As the extent of leaching increased, the samples became more open which should perhaps facilitate the evolution of gas at lower temperatures. However, the $T_{\max }$ values for $\mathrm{CH}, \mathrm{CHD}$ and $\mathrm{B}$ increased as the extent of leaching increased. This increase in $T_{\max }$ may represent an increase in binding strength of the CHA to the acid sites and/or a slower diffusion of the evolved gases out of the sample. A plausible explanation, given that the amount desorbed also decreases, is that the $\mathrm{CH}, \mathrm{CHD}$ and $\mathrm{B}$ are generated in the (decreasing) amounts of layered material remaining and then the molecules have to negotiate a more tortuous route to the gas phase through the silica fronds generated during acid leaching. Indeed, in SD-6M-95-60 the desorption maximum for benzene at $450{ }^{\circ} \mathrm{C}$ appears to have been removed. This could be attributed to the particular site associated with benzene production at this temperature having been dissolved away or rendered inaccessible as the silica fronds collapse together. Note that the samples prepared at $95^{\circ} \mathrm{C}$ all display a small 'prepeak' for the evolution of $\mathrm{CH}$ and CHD which diminishes with acid attack. This could mean that either the low temperature site responsible has been etched away or that the silica fronds are severely restricting access to it.

Once again the amount of unmodified CHA desorbed by the samples prepared using $1 \mathrm{M} \mathrm{HCl}$ increased with the severity of acid treatment in line with the increase in surface area (Figs. 4 and 10). Indeed the sample treated at $25^{\circ} \mathrm{C}$ for $120 \mathrm{~min}$ contained virtually no physisorbed CHA. Sample SD-1M-95-
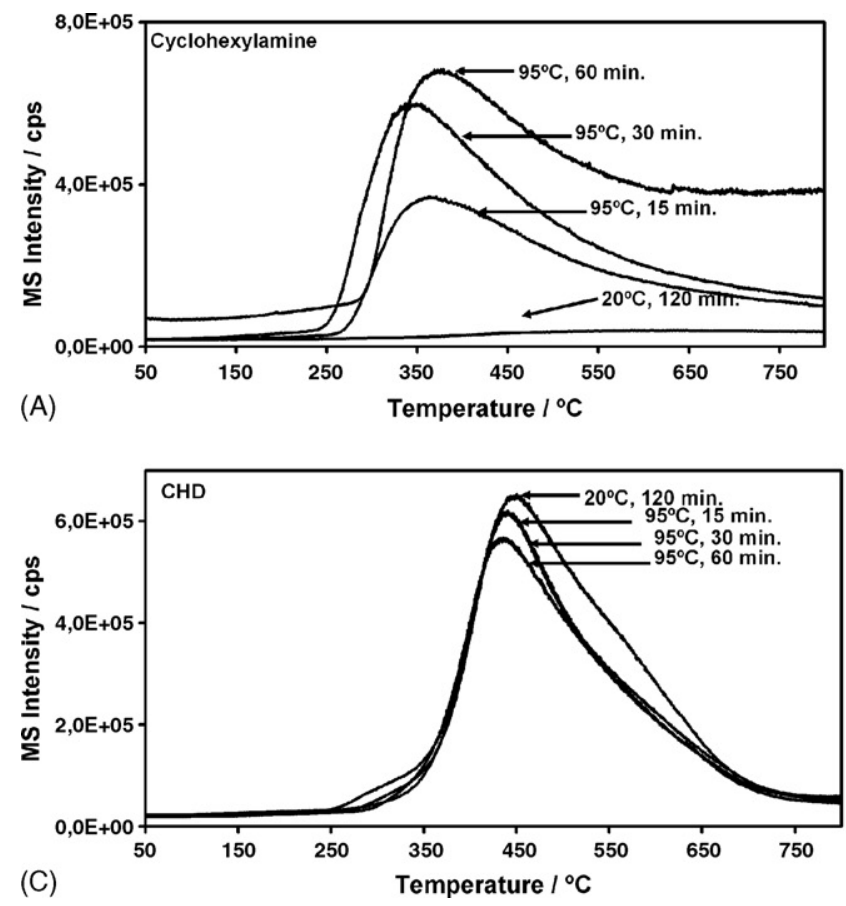

60 produced less $\mathrm{CH}$, but more $\mathrm{B}$, than the other samples whereas all the samples produced similar quantities of CHD. This dissimilarity is reflected in the lower weight loss displayed by SD-1M-95-60 in the $280-440{ }^{\circ} \mathrm{C}\left(0.29 \mathrm{mmol} \mathrm{g}^{-1}\right) \mathrm{com}-$ pared with the other samples $\left(0.65,0.62\right.$ and $0.52 \mathrm{mmol} \mathrm{g}^{-1}$ for SD-1M-25-120, SD-6M-95-15 and SD-6M-95-30, respectively). Unlike the samples discussed in the context of Fig. 9, the values of $T_{\max }$ for $\mathrm{CH}, \mathrm{CHD}$ and $\mathrm{B}$ (Fig. 10) were unaffected by treatment of Na-SD with $1 \mathrm{M} \mathrm{HCl}$. Moreover, the low temperature desorption peak for $\mathrm{B}$, at $450{ }^{\circ} \mathrm{C}$, has not been removed/blocked in these less extensively leached samples, perhaps providing support for the view that $\mathrm{CH}, \mathrm{CHD}$ and $\mathrm{B}$ were generated in the galleries associated with the undamaged layers.

The materials activated with $\mathrm{HCl}$ at the low temperature $20{ }^{\circ} \mathrm{C}$ (Figs. 9 and 10) displayed similar behaviour as anticipated from the characterization data presented above. The EGA data for $\mathrm{Na}-\mathrm{SD}$ activated for $30 \mathrm{~min}$ at $95{ }^{\circ} \mathrm{C}$, but with different acid concentrations is presented in Fig. 11. Two types of behaviour were evident and can be related to structural/ acidity features of the leached materials. The samples produced using weaker acids (1, 2 and 3M) evolved the same amount of CHA, as SD-6M-95-30 but more $\mathrm{CH}, \mathrm{CHD}$ and $\mathrm{B}$ which reflects the pronounced decrease in the total number of acidic sites on the sample treated with $6 \mathrm{M} \mathrm{HCl}\left(0.1 \mathrm{mmol} \mathrm{g}^{-1}\right)$. Note that SD-6M-95-30 also evolved a larger amount of unmodified CHA in line with the data in Fig. 9.

It is interesting to note, in the context of the catalytic results, that SD-3M-95-30, which was very effective at producing $p$ cymene, exhibited properties which are a combination of those produced under mild and severe leaching conditions. This material released similar amounts of $\mathrm{CH}$ to SD-6M-95-30 (i.e.
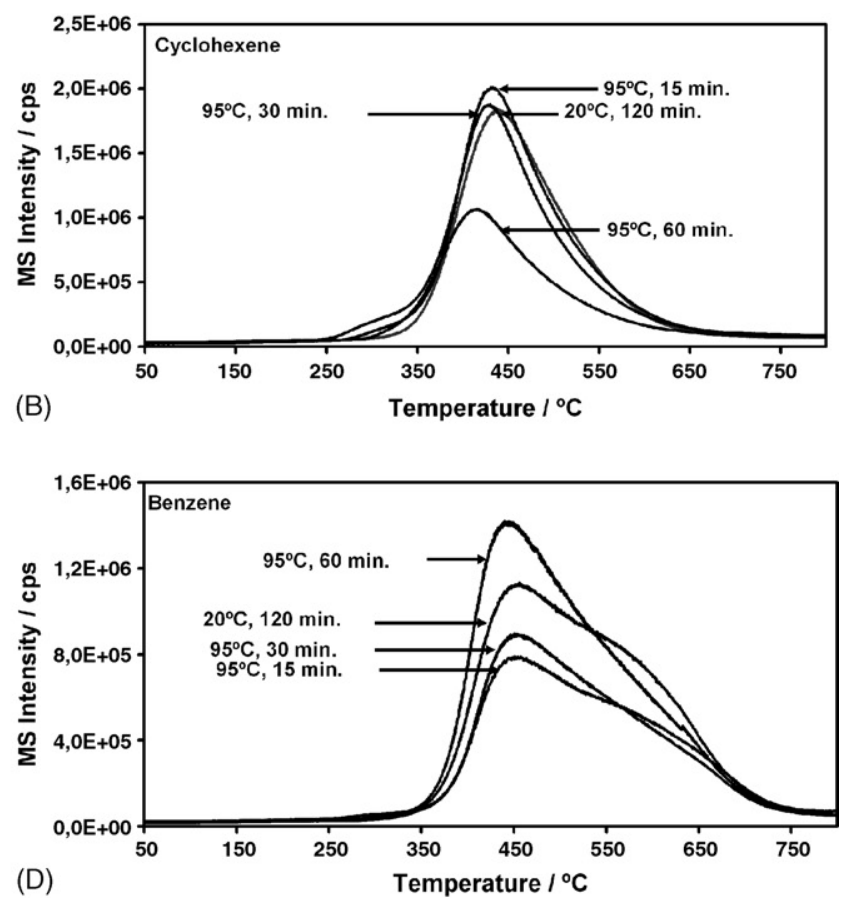

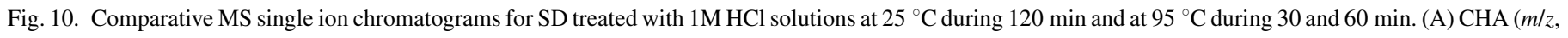
99), (B) $\mathrm{CH}(\mathrm{m} / \mathrm{z}, 54)$, (C) CHD $(\mathrm{m} / \mathrm{z}, 77)$ and (D) B $(\mathrm{m} / \mathrm{z}, 78)$. 

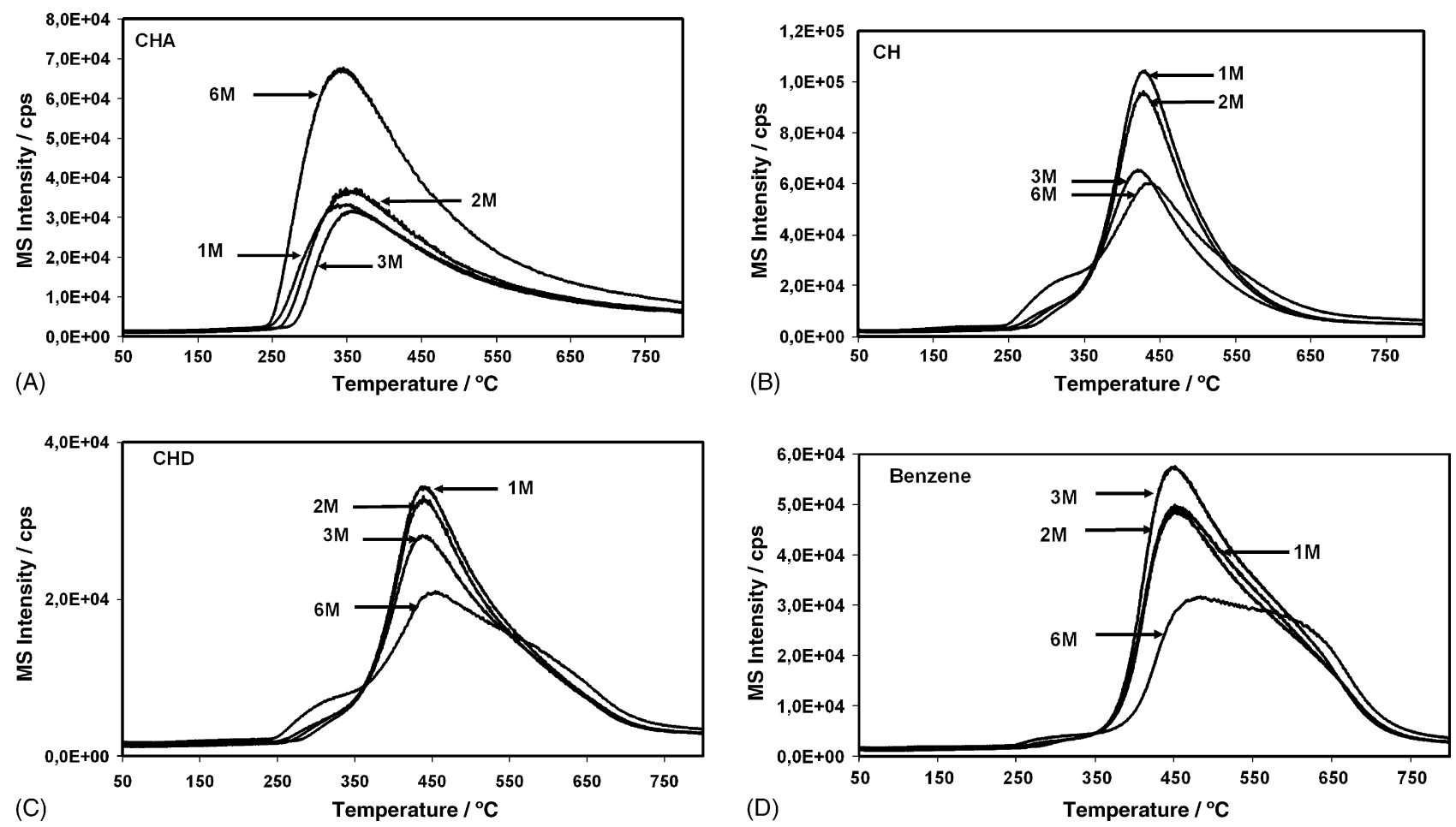

Fig. 11. Comparative MS single ion chromatograms for $\mathrm{SD}$ treated with $1,2,3$ and $6 \mathrm{M} \mathrm{HCl}$ solutions at $95^{\circ} \mathrm{C}$, during $30 \mathrm{~min}$. (A) $\mathrm{CHA}(\mathrm{m} / z, 99),(\mathrm{B}) \mathrm{CH}(\mathrm{m} / \mathrm{z}, 54)$, (C) $\mathrm{CHD}(\mathrm{m} / \mathrm{z}, 77)$ and (D) B $(\mathrm{m} / \mathrm{z}, 78)$.

less than samples produced using 1 and $2 \mathrm{M}$ acid), similar amounts of CHD to SD-1M-95-30 and SD-2M-95-30 yet more B than all the other acid activated materials. This may be of particular relevance given that dehydrogenation of a cyclohexadiene ring to an aromatic ring is critical in the formation of $p$ cymene from the terpinenes.

Controlled acid activation of clays offers materials with enhanced surface areas and total acidities yet a balance must be reached where the optimum levels of surface area and acidity for a particular process produces the maximum yield of the desired product. SD-3M-95-30 and SD-4M-95-15 seem to exhibit the required balance of these conflicting features. They have a high surface area together with a significant acidity combined with the ability to dehydrogenate ring compounds as shown by the generation of more benzene than the other leached materials.

\section{Conclusions}

Acid leaching of SD bentonite produces a very active catalyst which converts $90 \%$ of limonene in 15 min at $80{ }^{\circ} \mathrm{C}$. Similar transformation activity over $\mathrm{Al}^{3+}$ - and $\mathrm{Ni}^{2+}$-exchanged $\mathrm{SD}$ requires $15 \mathrm{~min}$ at $150{ }^{\circ} \mathrm{C}$ [39]. The yield of $p$-cymene maximised near $15 \%$ over SD-3M-95-30 and SD-4M-95-15 when the surface area was near $450 \mathrm{~m}^{2} \mathrm{~g}^{-1}$ but the acidity was relatively low but readily accessible to the reagent limonene. The yield of polymeric and non-volatile products was high at $50-55 \%$, which was two or three times the yield over the $\mathrm{Al}^{3+}$. and $\mathrm{Ni}^{2+}$-exchanged SD catalysts [39]. It is difficult to compare the production of non-volatile products with those of other catalysts because few authors provide relevant data. The lack of isomerization and dehydrogenation activity over the acidtreated samples of the low iron SAz-1 clay strongly suggests that the structural iron present in SD is responsible for the dehydrogenation role. This structural iron was most exposed/ active when the surface area was at its highest.

\section{Acknowledgements}

Financial support from Fundação de Ciência e Tecnologia (Portugal) and FEDER (POCTI/CMT/47619/2002) is gratefully acknowledged. C. Fernandes is grateful for the financial support provided by the European Social Fund under PRODEP Grant no. 05.03/MD/00276.017/03.

\section{References}

[1] A.B. Booth, J.S. Autenrieth, 3rd ed., Encyclopedia of Chemical Technology, vol. 19, Kirkothmer, 1969.

[2] H. Fiege, 5th ed., Ulmann's Encyclopedia of Industrial Chemistry, vol. A8, 1987.

[3] H. Sato, K. Kato, H. Shimuzu (Sumitomo Chemical Co.), Jpn. Kokai Tokyo, JP 06,340,559 (5 April 1993).

[4] BASF, US 3,555,103 (1967).

[5] A.M. Costa, J.A. Lourenço, Tecnologia dos Resinosos, LNETI, 1982.

[6] J.A. Lourenço, Personal communication, 1999.

[7] J.A. Lourenço, M.S. Casquilho, in: Proceedings of Encontro sobre o Pinheiro Manso, Sociedade Portuguesa de Ciências Florestais, Tróia, 1988.

[8] V. Krishnasamy, L.M. Yeddanapalli, Can. J. Chem. 54 (1976) 3458.

[9] To Hercules Powder Co., US 2,402,898 (1946).

[10] To Am. Cyanamid Co., US 2,272,711 (1942). 
[11] P.A. Weyrich, W.F. Hoelderich, Appl. Catal. A 158 (1997) 145-162.

[12] P.A. Weyrich, H. Trevino, W.F. Hoelderich, W.M.H. Sachtler, Appl. Catal. A 163 (1997) 31-44.

[13] A. De Stefanis, G. Perez, O. Ursini, A.A.G. Tomlinson, Appl. Catal. A 132 (1995) 353-365.

[14] D.R. Brown, C.N. Rhodes, Catal. Lett. 45 (1997) 35-40.

[15] C. Breen, A.J. Moronta, Clay Miner. 36 (2001) 467-472.

[16] N. Besun, F. Ozkhan, G. Gunduz, Appl. Catal. A 224 (2002) 285-297.

[17] H. Komae, J. Sci. Hiroshima Uni. A 24 (1960) 699.

[18] M. Frenkel, L. Heller-Kallai, Clays Clay Miner. 31 (1983) 92-96.

[19] A. Vaccari, Catal. Today 41 (1998) 53-71.

[20] M. Janek, P. Komadel, Geologica Carpathica Ser. Clays 44 (1993) 59-64.

[21] C. Breen, F.D. Zahoor, J. Madejova, P. Komadel, J. Phys. Chem. B 101 (1997) 5324-5331.

[22] E.J. Ferraz, J.B. Silva, Acta Universitatis Carolinae Geológica 38 (2-4) (1994) 175-182.

[23] M.P. Ferreira, L.M. Serrano, in: Proceedings of the Congresso HispanoLuso-Americano de Geologia Económica, vol. S.6, 1971, p. 225.

[24] M. Brotas de Carvalho, J. Pires, A.P. Carvalho, Microporous Mater. 6 (1996) 65-77.

[25] P. Castilho, G. Faria, C. Fernandes, C. Breen, M.R. Carrott, I. Cansado, A. Candeias, in: Proceedings of the First Latin American Clay Conference, vol. II, 2000, pp. 134-136.

[26] C. Breen, R. Watson, P. Komadel, J. Madejova, Z. Klapyta, Langmuir 13 (1997) 6473-6497.

[27] A.U. Dogan, M. Dogan, M. Onal, Y. Sarikaya, A. Aburub, D.E. Wurster, Clays Clay Miner. 54 (2006) 62-66.

[28] C.N. Rhodes, D.R. Brown, Clay Miner. 29 (1994) 799-801.

[29] J. Madejová, I. Kraus, P. Komadel, Geologica Carpathica Ser. Clays 4 (1) (1995) 23-32.
[30] S.J. Oh, D.C. Cook, H.E. Townsend, Hyperfine Interact Ions 112 (1998) $59-65$.

[31] J. Madejová, J. Bujdák, M. Janek, P. Komadel, Spectrochim. Acta A 54 (1998) 1397-1406.

[32] F. Rouquerol, J. Rouquerol, K.S.W. Sing, Adsorption by Powders \& Porous Solids, Academic Press, London, 1999.

[33] I. Novak, M. Gregor, Proc. Int. Clay Conf. Tokyo (1969) 851.

[34] C.N. Rhodes, D.R. Brown, Catal. Lett. 24 (1994) 285-291.

[35] J.A. Ballantine, P. Graham, I. Patel, J.H. Purnell, K.J. Williams, J.M. Thomas, in: L.G. Schultz, H. van Olphen, F.A. Mumpton (Eds.), Proc. Int. Clay Conf., Denver, 1985, The Clay Minerals Society, Bloomington, IN, 1987, p. 311.

[36] P. Komadel, M. Janek, J. Madejová, A. Weekes, C. Breen, J. Chem. Soc., Faraday Trans. 93 (1997) 4207-4210.

[37] A.F. Thomas, Y. Bessière, Nat. Prod. Rep. 6 (3) (1989) 291-309.

[38] A. Vaccari, Appl. Clay Sci. 14 (1999) 161-198.

[39] C. Catrinescu, C. Fernandes, P. Castilho, C. Breen, Appl. Catal. A Gen. 311 (2006) 172-184.

[40] R. Crockett, E. Roduner, J. Chem. Soc., Perkin Trans. II (1994) 347-350.

[41] M.P. Hart, D.R. Brown, J. Mol. Catal. A 212 (2004) 315-321.

[42] C. Cativiela, F. Figueras, J.M. Fraile, J.I. Garcia, M. Gil, J.A. Mayoral, L.C. de Menorval, E. Pires, in: M. Guisnet et al. (Ed.), Stud. Surf. Sci. Catal., vol. 78, Heterogeneous Catalysis and Fine Chemicals III, Elsevier, The Netherlands, 1993, p. 495.

[43] C. Breen, J. Forsyth, J. Yarwood, T. Hughes, Phys. Chem. Chem. Phys. 2 (2000) 2887-3892.

[44] J.A. Ballantine, P. Graham, I. Patel, J.H. Purnell, M. Rayanakprn, J. Williams, J.M. Thomas (1985), in: L.G. Schultz, H. van Olphen, F.A. Mumpton (Eds.), Proc. Int. Clay Conf. Denver, The Clay Minerals Society, Bloomington, IN, 1987, p. 311.

[45] J. Bovey, W. Jones, J. Mater. Chem. 5 (1995) 2027-2035. 